\title{
Prevention and empathetic dentistry vital in managing child dental caries
}

Dentists should always focus on prevention and empathetic care when treating children with tooth decay, according to preliminary results from a large-scale and long-running trial of how best to treat dental caries in children.

Delegates at the British Society of Paediatric Dentistry's (BSPD) annual conference held from 11 to 14 September 2018 in Dundee were presented with preliminary results of the FiCTION trial ${ }^{1}$ which was set up to test three different approaches to the management of tooth decay in children.

FiCTION (Filling Children's Teeth: indicated or not) began 10 years ago in Dundee as a multi-centre randomised controlled trial involving seven locations - Cardiff, Glasgow, Leeds, Newcastle, Sheffield, London and Dundee - and 1,144 children aged 3-7 years.

The trial recruited more than 70 general dentists across the UK who tested out each of three approaches:

- Conventional (drill and fill) with prevention

- Biological management (sealing in) with prevention

- Best practice prevention alone.

The trial team are currently awaiting feedback from their funders - the National Institute for Health Research Health Technology Assessment (NIHR HTA) programme - which must endorse their interpretation of the results. Only when they have the approval of the funders can the results be made public, which is expected before the end of 2018 .

However, delegates at the conference heard about the trial in detail and learned that a key finding was that the trust

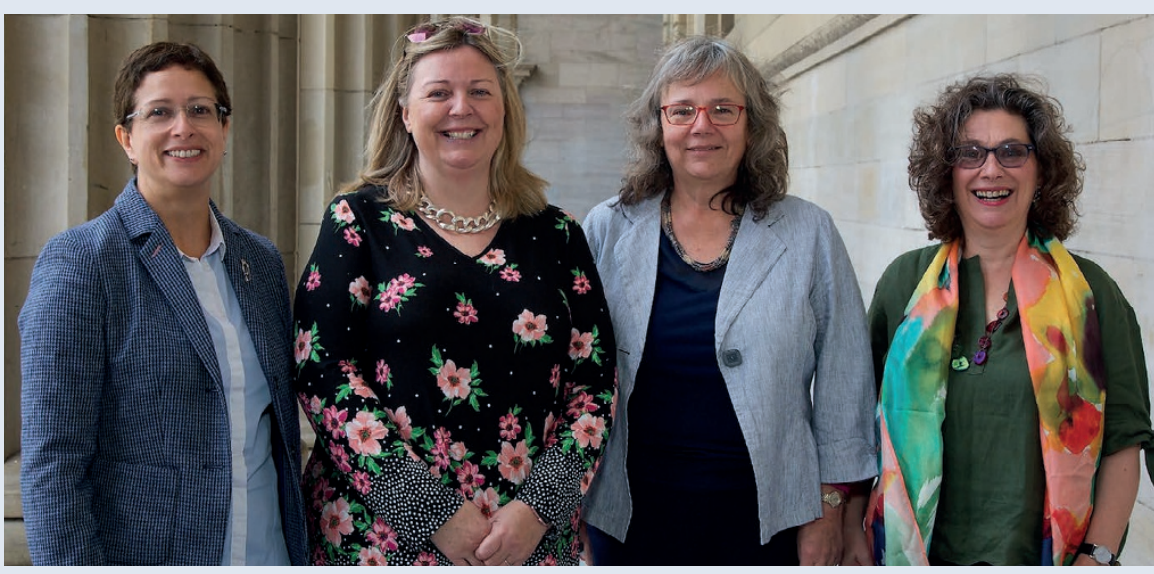

(I-r) Professor Nicola Innes, Professor Gail Douglas, Professor Anne Maguire and Professor Jan Clarkson

engendered by the dentist who is providing the care and delivering preventive advice, is critical to any outcome. They were also told that once a child has developed caries, they are likely to experience pain and/or infection so intensive prevention should be targeted at the child and his/her parents.

Professor Jan Clarkson, Chair of the Conference Organising Committee as well as a lead investigator for the FiCTION trial, said: 'Our findings will now feed through into advice for the dental profession. We are working to ensure it is included in updates of the Scottish Dental Clinical Effectiveness Programme $(\mathrm{SCDEP})^{2}$ and Delivering Better Oral Health ${ }^{3}$.

Public Health Dentist, Zoe Marshman - a Professor and Honorary Consultant in Sheffield - was one of the core team who led on the patient and parent perspectives.

Professor Marshman said of the findings: 'As well as looking at the clinical perspective, we also focused on pain, infection, anxiety, quality of life and health economics. We interviewed children, parents and dental professionals about their views on the acceptability of treatment and found that, with the child-centred patient management, all treatments were considered acceptable.'

Professor Nicola Innes, also Dundeebased and a lead investigator along with Professors Anne Maguire, Gail Douglas and Jan Clarkson, said: 'Successfully delivering this complex research is a testament to collaboration across the paediatric dental community and the willingness of general practitioners to participate in research and contribute to improving patient care.'

Claire Stevens, BSPD spokeswoman, said: 'One of the key messages of this trial is the importance of evidence-based prevention which must underpin any approach to caries.'

1. University of Dundee. FiCTION trial: https://dentistry. dundee.ac.uk/nihr-hta-fiction-trial (accessed 18 September 2018)

2. Scottish Dental Clinical Effectiveness Programme. http://www.sdcep.org.uk/ (accessed 18 September 2018).

3. Public Health England \& Department of Health. Delivering Better Oral Health. March 2017. Available at https://assets.publishing.service.gov.uk/government/uploads/system/uploads/attachment_data/ file/605266/Delivering_better_oral_health.pdf (accessed 18 September 2018).

\section{Workshop for new authors and peer reviewers}

E further workshop for new authors and peer reviewers is being held at the BDA headquarters at 64 Wimpole Street, London on Tuesday 23 October 2018 starting at 11 am. The joint programme between the $B D J$ portfolio and the British Writers and Editors Forum is open to everyone and the cost for

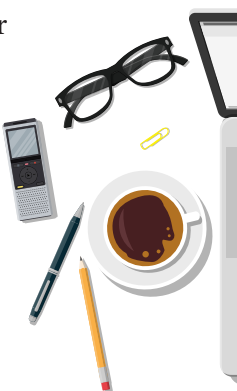

BRITISH DENTAL JOURNAL | VOLUME 225 NO. 7 | OCTOBER 122018 the day is $£ 40$ ( $£ 20$ for full-time students) to include lunch and five hours of eCPD in accordance with GDC development outcomes.

Further information including the provisional programme is available by emailing stephen.hancocks@bda.org. 